\title{
APLICAÇÃO DE UM PROTOCOLO DE AVALIAÇÃO AMBIENTAL RÁPIDA EM DOIS RESERVATÓRIOS DO SEMIÁRIDO BRASILEIRO
}

\author{
BRITO, M.T.S. ${ }^{1 *}$; NASCIMENTO FILHO, S.L. ${ }^{1} ;$ VIANA, G.F.S. ${ }^{2} \&$ MELO JÚNIOR, M. ${ }^{1}$
1. Programa de Pós-Graduação em Ecologia, Universidade Federal Rural de Pernambuco, Recife, PE, Brasil. \\ 2. Universidade Federal Rural de Pernambuco/Unidade Acadêmica de Serra Talhada, Serra Talhada, \\ PE, Brasil. \\ *Corresponding author: maiaratabatha@hotmail.com
}

\begin{abstract}
Brito, M.T.S.; Nascimento filho, S.L.; Viana, G.F.S. \& Melo júnior, M., (2016). Aplicação de um protocolo de avaliação ambiental rápida em dois reservatórios do semiárido brasileiro. Braz. J. Aquat. Sci. Technol. 20(1). elSSN 19839057. DOI: 10.14210/bjast.v20n1. In the semi-arid region of Brazil, artificial reservoirs are extremely important ecological and social ecosystems. Due to pressures caused by long periods of pluviometric irregularity, the reservoirs Cachoeira I and Barra, located in the interior of Pernambuco (Brazil), have been subject to very significant changes, marked mainly by the reduction of stored water volume, seasonal changes in the abiotic parameters (example: $\mathrm{pH}$, turbidity), reduction of riparian vegetation and absence of macrophytes. All these changes were observed in this study through the use of an auxiliary monitoring tool, a rapid assessment protocol adapted for lentic ecosystems of semiarid, capable of detecting numerous types of environmental changes.
\end{abstract}

Keywords: Monitoring, Caatinga, Diversity of habitats, Freshwater environments, Environmental changes.

Considerada recurso de indiscutível importância para a sobrevivência e manutenção da dignidade humana, a água é para algumas regiões do Brasil um recurso escasso. Na região semiárida, onde a seca se caracteriza como um fenômeno constante, os reservatórios artificiais são ecossistemas de extrema importância ecológica e social. Nos últimos anos, o crescimento populacional desordenado e o uso excessivo deste recurso tem destacado o papel do homem como agente transformador, sendo responsável por grandes perdas na integridade de diversos mananciais ao redor do mundo (Machado, 2003; Togoro, 2006). Segundo Callisto et al. (2002), o impacto antrópico sobre os ecossistemas aquáticos está entre os principais responsáveis pela deterioração da qualidade ambiental de bacias hidrográficas; acarretando, consequentemente, a perda da capacidade de abastecimento de populações, da manutenção da vida aquática e do seu uso para recreação (Figueirêdo et al., 2007). Porém, além da atividade humana, reservatórios expostos a condições climáticas extremas, como elevadas temperaturas e poucas e irregulares precipitações pluviométricas, podem vir a reduzir expressivamente o seu volume hídrico, chegando a tornar-se eutrofizados, dificultando a utilização deste recurso (Figueirêdo et al., 2007; Lodi et al., 2011; Barbosa et al., 2012).

Diante deste cenário, torna-se de fundamental importância o monitoramento das alterações ambientais, seja realizado por métodos físico-químicos usuais, organismos bioindicadores ou por meio de ferramentas auxiliares, como os protocolos de avaliação rápida (Callisto et al., 2001; Togoro, 2006; Rodrigues et al., 2010). De acordo com Togoro (2006), muitas são as alterações que podem ser identificadas por meio dos protocolos, tais como o assoreamento, a destruição da vegetação ciliar, a poluição e a pesca excessiva. No Brasil, o uso de ferramentas empíricas é cada vez mais frequente, tanto para avaliar ambientes lóticos como lênticos (Brito et al., 2011; Firmino et al., 2011; Vargas e Ferreira Júnior, 2012; França et al., 2013). Neste contexto, este estudo buscou avaliar a qualidade ambiental de dois reservatórios da região semiárida de Pernambuco, por meio de um Protocolo de avaliação rápida da diversidade de habitats e alteração ambiental (Hannaford et al., 1997), adaptado por Callisto et al. (2002) e, posteriormente, por Brito et al. (2011), com a finalidade de identificar as principais alterações que possam estar interferindo na dinâmica temporal destes ecossistemas aquáticos artificiais do semiárido nordestino.

Os ecossistemas estudados estão localizados na cidade de Sertânia, semiárido de Pernambuco ( $8^{\circ} 4^{\prime} 28^{\prime \prime} S$, 37 $\left.15^{\prime} 53^{\prime \prime} \mathrm{W}\right)$. O reservatório Cachoeira I apresenta capacidade de acumulação total de $5.950 .000 \mathrm{~m}^{3}$ de água, enquanto que, para o reservatório Barra, esta capacidade é de $2.738 .160 \mathrm{~m}^{3}$ (APAC, 2014). Além de serem responsáveis pelo abastecimento público da cidade, os reservatórios em questão caracterizam-se por apresentar usos múltiplos como a irrigação, abastecimento urbano, dessedentação animal, pesca e recreação. O protocolo de 
avaliação rápida da diversidade de habitats e alteração ambiental utilizado neste estudo foi adaptado para ecossistemas lênticos da região semiárida por Brito et al. (2011) (Tabela 1). De acordo com Rodrigues et al. (2008), a adequação dos protocolos já existentes é necessária, visto a necessidade de adaptá-los às especificidades regionais e locais, já que as características dos corpos d'água mudam em função de fatores como clima, relevo, geologia e vegetação.

Tabela 1 - Protocolo de avaliação rápida e diversidade de hábitats utilizado no estudo, adaptado por Brito et al. (2011).

\begin{tabular}{|c|c|c|c|c|}
\hline Parâmetros & 5 pontos & 3 pontos & 2 pontos & 0 pontos \\
\hline $\begin{array}{l}\text { 1. Tipos } \\
\text { principais de } \\
\text { ocupação } \\
\text { das margens } \\
\text { do corpo } \\
\text { d'água. }\end{array}$ & $\begin{array}{l}\text { Cobertura natural } \\
\text { (Caatinga nativa). }\end{array}$ & $\begin{array}{l}\text { Campo de } \\
\text { agricultura, } \\
\text { monocultura, } \\
\text { Reflorestamento. }\end{array}$ & $\begin{array}{l}\text { Campo } \\
\text { pastagem } \\
\text { (caprinos } \\
\text { outros). }\end{array}$ & $\begin{array}{l}\text { Residencial, } \\
\text { comercial e/ou } \\
\text { industrial. }\end{array}$ \\
\hline $\begin{array}{l}\text { 2. Alterações } \\
\text { antrópicas do } \\
\text { entorno. }\end{array}$ & Ausente. & $\begin{array}{l}\text { Irrigação; } \\
\text { Lavagem } \\
\text { roupas } \\
\text { animais. }\end{array}$ & $\begin{array}{l}\text { Recreação; } \\
\text { Alteração } \\
\text { origem } \\
\text { doméstica. }\end{array}$ & $\begin{array}{l}\text { Alteração de } \\
\text { origem urbana. }\end{array}$ \\
\hline $\begin{array}{l}\text { 3. Cobertura } \\
\text { vegetal no } \\
\text { entorno. }\end{array}$ & $\begin{array}{l}\text { Total (Vegetação } \\
\text { nativa). }\end{array}$ & $\begin{array}{l}\text { Parcial } \\
\text { (vegetação } \\
\text { agrícola). }\end{array}$ & $\begin{array}{l}\text { Área de } \\
\text { reflorestamento. }\end{array}$ & Ausente. \\
\hline $\begin{array}{l}\text { 4. Odor da } \\
\text { água. }\end{array}$ & Nenhum. & Algas. & Esgoto. & Óleo industrial. \\
\hline $\begin{array}{l}\text { 5. Cor da } \\
\text { água. } \\
6 \text {. Tipo de } \\
\text { fundo. }\end{array}$ & $\begin{array}{l}\text { Transparente. } \\
\text { Pedras/cascalhos. }\end{array}$ & Cor de ferrugem. & Lamoso. & $\begin{array}{l}\text { Opaca } \\
\text { colorida. } \\
\text { Artificial } \\
\text { (cimento). }\end{array}$ \\
\hline $\begin{array}{l}7 . \\
\text { Diversidade } \\
\text { de hábitats. }\end{array}$ & $\begin{array}{l}\text { Mais de } 50 \% \text { com } \\
\text { hábitats } \\
\text { diversificados: } \\
\text { pedaços } \\
\text { troncos } \\
\text { submersos, } \\
\text { cascalhos ou } \\
\text { outros hábitats } \\
\text { estáveis }\end{array}$ & $\begin{array}{l}\text { Entre } 30 \text { a } 50 \% \\
\text { de hábitats } \\
\text { diversificados: } \\
\text { hábitats } \\
\text { adequados para } \\
\text { manutenção das } \\
\text { populações de } \\
\text { organismos } \\
\text { aquáticos. }\end{array}$ & $\begin{array}{l}\text { Entre } 10 \text { a } 30 \% \\
\text { de hábitats } \\
\text { diversificados: } \\
\text { disponibilidade } \\
\text { insuficiente; } \\
\text { substratos } \\
\text { modificados. }\end{array}$ & $\begin{array}{l}\text { Menos de } 10 \% \\
\text { de hábitats } \\
\text { diversificados: } \\
\text { ausência de } \\
\text { hábitats óbvia; } \\
\text { substrato } \\
\text { rochoso } \\
\text { instável. }\end{array}$ \\
\hline $\begin{array}{l}\text { 8. Presença } \\
\text { de vegetação } \\
\text { ciliar }\end{array}$ & $\begin{array}{l}\text { Acima de } 90 \% \\
\text { com vegetação } \\
\text { nativa: incluindo } \\
\text { árvores, arbustos } \\
\text { ou macrófitas; } \\
\text { mínima evidência } \\
\text { de } \\
\text { desflorestamento; } \\
\text { todas as plantas } \\
\text { atingindo a altura } \\
\text { normal. }\end{array}$ & $\begin{array}{l}\text { Entre } 70 \text { e } 90 \% \\
\text { com vegetação } \\
\text { ripária nativa: } \\
\text { desflorestamento } \\
\text { evidente mas } \\
\text { não afetando o } \\
\text { desenvolvimento } \\
\text { da vegetação; a } \\
\text { maioria das } \\
\text { plantas atingindo } \\
\text { a altura normal. }\end{array}$ & 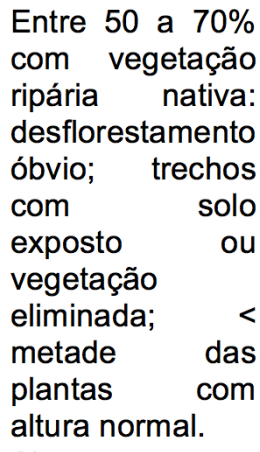 & $\begin{array}{l}\text { Menos de } 50 \% \\
\text { de mata ciliar } \\
\text { nativa: } \\
\text { desflorestament } \\
\text { o r muito } \\
\text { acentuado. }\end{array}$ \\
\hline $\begin{array}{l}\text { 9. Presença } \\
\text { de plantas } \\
\text { aquáticas }\end{array}$ & $\begin{array}{l}\text { Pequenas } \\
\text { macrófitas } \\
\text { aquáticas } \\
\text { musgos } \\
\text { distribuídos } \\
\text { leito. }\end{array}$ & $\begin{array}{l}\text { Macrófitas } \\
\text { aquáticas ou } \\
\text { algas } \\
\text { filamentosas ou } \\
\text { musgos } \\
\text { distribuídos no } \\
\begin{array}{l}\text { reservatório, } \\
\text { substrato com } \\
\text { perifiton. }\end{array}\end{array}$ & $\begin{array}{l}\text { Algas } \\
\text { filamentosas ou } \\
\text { macrófitas em } \\
\text { poucas pedras, } \\
\text { perifíton } \\
\text { abundante e } \\
\text { biofilme. }\end{array}$ & $\begin{array}{l}\text { Ausência de } \\
\text { vegetação } \\
\text { aquática ou } \\
\text { grandes bancos } \\
\text { de macrófitas } \\
\text { (p. } \quad \text { ex. } \\
\text { aguapés). }\end{array}$ \\
\hline
\end{tabular}


O estudo foi realizado bimensalmente entre 0 período de agosto de 2012 a março de 2014, em três pontos aleatórios de cada reservatório, a fim de se obter uma visão mais ampla de todo o ecossistema. Os parâmetros considerados no protocolo foram pontuados com os números $5,3,2$ e 0 com base na observação das condições de habitats, e quanto maior a pontuação, melhor a condição de cada parâmetro. O resultado final foi obtido por meio do somatório das médias dos pontos atribuídos a cada parâmetro, oferecendo assim um valor total para cada mês analisado. Vale ressaltar que, pelo fato de tratar-se de uma ferramenta empírica de avaliação, o protocolo foi aplicado sempre pelos mesmos observadores. Dados de temperatura, oxigênio dissolvido, $\mathrm{pH}$, sólidos totais dissolvidos e salinidade também foram mensurados, através de uma sonda multiparâmetro U-52, marca Horiba.

O acompanhamento periódico dos ecossistemas artificiais mostrou uma variação sazonal nos parâmetros avaliados em ambos os reservatórios. A Tabela 2 apresenta a pontuação obtida através da aplicação do protocolo para cada parâmetro analisado, no decorrer dos meses e em ambos os ecossistemas, assim como sua respectiva classificação e os valores médios para os parâmetros abióticos.

Tabela 2 - Pontuação e classificação dos reservatórios de acordo com o protocolo de avaliação ambiental. AE: alterações extremas (0 - 9); AM: alterações moderadas (10 - 18); AR: alterações reduzidas (19 - 26). Valores mensais dos parâmetros abióticos. Temperatura: ${ }^{\circ} \mathrm{C}$; Potencial hidrogeniônico: $\mathrm{pH}$; Sólidos totais dissolvidos (mg L-1): TDS; Salinidade: ppt; Oxigênio dissolvido (mg L $\left.\mathrm{L}^{-1}\right)$ : DO. * ausência de amostragem.

\begin{tabular}{|c|c|c|c|c|c|c|c|c|c|c|c|c|}
\hline \multirow{2}{*}{$\begin{array}{l}\text { Ano } \\
\text { Mês }\end{array}$} & \multicolumn{6}{|c|}{ Cachoeira I } & \multicolumn{6}{|c|}{ Barra } \\
\hline & $\begin{array}{c}\text { Pontuação } \\
\text { Classificação }\end{array}$ & ${ }^{\circ} \mathrm{C}$ & $\mathrm{pH}$ & TDS & ppt & DO & $\begin{array}{l}\text { Pontuação } \\
\text { Classificação }\end{array}$ & ${ }^{\circ} \mathrm{C}$ & $\mathrm{pH}$ & TDS & ppt & DO \\
\hline 2012 & & & & & & & & & & & & \\
\hline Agosto & 24 - AR & 27,5 & 8,7 & 0,69 & 0,05 & 13,8 & 17 - AM & 26,0 & 8,2 & 0,6 & 0,05 & 9,5 \\
\hline $\begin{array}{c}\text { Outubro } \\
2013\end{array}$ & $24-A R$ & 28,1 & 8,6 & 0,78 & 0,06 & 8,25 & $16-\mathrm{AM}$ & 30,2 & 9 & 0,86 & 0,07 & 12,2 \\
\hline Janeiro & $19-A R$ & 34,3 & 7,9 & 0,91 & 0,07 & 14,86 & $11-\mathrm{AM}$ & 32,1 & 9,3 & 1,86 & 0,15 & 22,5 \\
\hline Fevereiro & $19-A R$ & 29,3 & 8,1 & 0,66 & 0,07 & 36,9 & $11-\mathrm{AM}$ & 33,0 & 9,2 & 2,6 & 0,22 & 22,8 \\
\hline Abril & $19-A R$ & 29 & 8,6 & 0,89 & 0,07 & 6,60 & $9-\mathrm{AE}$ & 25,4 & 8,3 & 5,18 & 0,46 & 12,1 \\
\hline Julho & $18-\mathrm{AM}$ & 28,4 & 7,2 & 1,02 & 0,83 & 12,35 & $0-A E$ & * & * & * & * & * \\
\hline Setembro & 17 - AM & 26,3 & 5,7 & 1,21 & 0,93 & 9,54 & $0-A E$ & * & * & * & * & * \\
\hline Outubro & 17 - AM & 27,1 & 7 & 1,3 & 0,103 & 8,92 & $0-\mathrm{AE}$ & * & * & * & * & * \\
\hline $\begin{array}{l}\text { Dezembro } \\
2014\end{array}$ & $17-\mathrm{AM}$ & 30,2 & 7,6 & 1,31 & 0,1 & 11,00 & 17 - AM & 29,0 & 5,1 & 0,13 & 0,01 & 7,9 \\
\hline Março & * & * & * & * & * & * & $17-\mathrm{AM}$ & 27,7 & 5,9 & 0,98 & 0,08 & 5,8 \\
\hline
\end{tabular}

Inicialmente, entre os meses de agosto de 2012 a abril de 2013, o reservatório Cachoeira I apresentou alterações consideradas reduzidas quanto à diversidade de habitats, além de outras marcadas, principalmente, por alterações na cor da água, tipo de fundo e ausência de vegetação ciliar e de macrófitas aquáticas. Tais alterações, possivelmente, transparecem a dificuldade que o ecossistema apresentou em permanecer equilibrado frente à grande estiagem enfrentada na região desde o início de 2012. Além disso, ainda foi possível observar a presença de vegetação natural no entorno do reservatório e, além disso, a água permaneceu sem nenhum odor.

Nos demais meses as alterações registradas foram consideradas moderadas, sendo marcadas pela redução expressiva da cobertura vegetal do entorno (parâmetro que mais variou neste ambiente), vegetação ciliar e de plantas aquáticas, parâmetros estes que apresentaram as menores pontuações médias durante o estudo (Figura 1). Ao mesmo tempo, os sólidos totais dissolvidos e a salinidade apresentaram aumentos consideráveis (Tabela 2). Estas mudanças podem ter sido influenciadas pela redução do volume de água do manancial em decorrência da seca, o que acarretou também a diminuição do uso da água para irrigação.

Enquanto isso, o reservatório de Barra foi caracterizado por apresentar impactos classificados entre moderados e extremos. As características do ambiente que o levaram a tal classificação também podem ser consideradas consequências das peculiaridades climáticas próprias da região, como a baixa profundidade do ecossistema, poucas e irregulares chuvas e altas temperaturas. Entre agosto de 2012 e abril de 2013, destacaram-se alterações como a perda de diversidade de habitats e vegetação ciliar. 

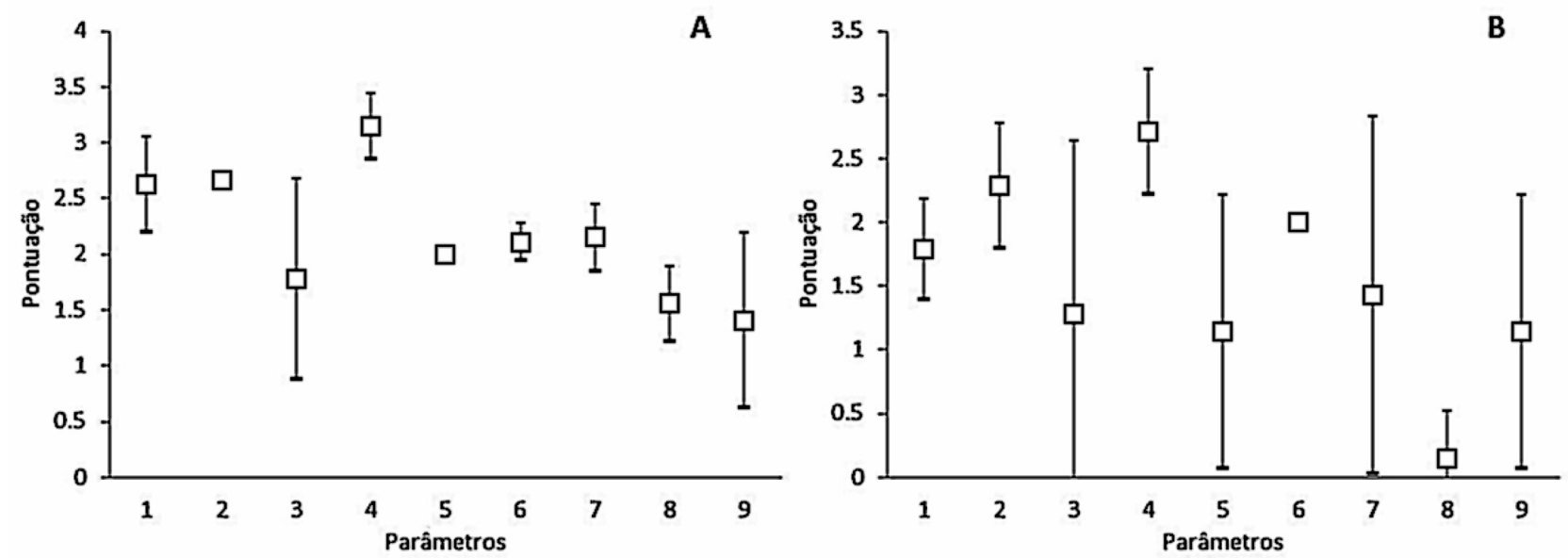

Figura 1 - Média e desvio padrão das pontuações registradas para cada parâmetro do protocolo. A, reservatório Cachoeira I e B, reservatório Barra. As descrições de cada parâmetro podem ser obtidas na Tabela 1 deste artigo.

Neste período, o $\mathrm{pH}$ apresentou-se alcalino $(\mathrm{pH} 9,3) \mathrm{e}$ os sólidos totais dissolvidos (5,18 TDS) e a salinidade $(0,46 \mathrm{ppt})$ alcançaram os seus maiores valores.

Todas estes fatores levaram o ambiente a entrar em estado de colapso e permanecer seco entre os meses de julho a outubro de 2013, momento em que todos os parâmetros foram caracterizados com a menor pontuação, refletindo alterações extremas no reservatório. De modo geral, a ausência de vegetação ciliar e modificações na cor da água foram os parâmetros que apresentaram menor pontuação média neste ambiente (Figura 1).

Com o retorno das chuvas na região, em dezembro de 2013, a vegetação ciliar retornou o seu desenvolvimento no reservatório Barra, mesmo que em pequenas porções da margem; suas águas apresentaram-se menos turvas e a diversidade de habitats disponíveis para a diversificação da vida aquática se multiplicou, passando então a ser considerado um ambiente com alterações moderadas, visto que ainda não havia se recuperado totalmente da pressão sofrida. Mudanças nos parâmetros abióticos também foram observadas, como diminuição do $\mathrm{pH}$, que tornou-se ácido, da salinidade e dos sólidos totais dissolvido (Tabela 2).

Como foi possível observar no estudo, a ausência de plantas aquáticas e a redução da cobertura vegetal do entorno e vegetação ciliar foram características particulares de ambos os ambientes. Ao mesmo tempo, foi observado que pesar da ausência de macrófitas, a água dos reservatórios permaneceu esverdeada, o que indica proliferação de fitoplâncton (florações algais).

Estas condições podem ter acarretado na diminuição da diversidade de microhábitats necessários à diversificação da vida da micro e macrofauna presente em ecossistemas dos reservatórios, alterando assim toda a estrutura trófica dos mananciais (Firmino et al., 2011). De modo geral, qualquer desestruturação do ambiente físico-químico de corpos d'água continentais pode conduzir à alterações na dinâmica natural das suas comunidades biológicas (Togoro, 2006; Nogueira et al., 2010).

Apesar de tratar-se de um método empírico de avaliação, segundo Firmino et al. (2011), os protocolos de avaliação rápida podem ser considerados instrumentos de diagnóstico ambiental objetivos e de baixo custo, porém sem perda da qualidade da informação. De modo geral, independentemente do método utilizado, monitorar as condições, estrutura e o funcionamento dos ecossistemas aquáticos continentais permite aos estudiosos entendê-los e, assim, desenvolver ações de manejo que os protejam (Callisto et al., 2001). Porém, Rodrigues et al. (2008) destacam que os protocolos de avaliação rápida, além de avaliar a qualidade da água, como nos métodos tradicionais de monitoramento, permitem uma visão geral do meio físico, refletindo o verdadeiro estado do corpo d'água, e dando à avaliação um caráter mais holístico.

Baseado no que foi exposto, pode-se concluir que o acompanhamento dos reservatórios por meio da aplicação do protocolo de avaliação ambiental rápida e diversidade de hábitats revelou a reação dos ecossistemas frente às principais pressões sofridas, tanto por parte da ação antrópica, quanto por parte das condições climáticas do semiárido, esta última bem mais severa.

No geral, as principais alterações observadas foram relativas à ausência de plantas aquáticas e vegetação ciliar, além da água turva e esverdeada durante boa parte do estudo, parâmetros relacionados à diminuição do volume de água armazenada em decorrência da estiagem. O protocolo utilizado demonstrou ser uma boa ferramenta de monitoramento, capaz de 
auxiliar as demais ações de manejo realizadas pelas agências públicas e privadas que atuam no monitoramento dos recursos hídricos. Índices bióticos que utilizem organismos indicadores da qualidade da água podem ser utilizados em conjunto ao protocolo, incrementando o estudo que permanece sendo considerado de metodologia prática, eficaz e barata.

\section{REFERÊNCIAS BIBLIOGRÁFICAS}

Agência Pernambucana de Águas e Clima, Recife. Último acesso: 27 Outubro 2013. Disponível em: http://www.apac.pe.gov.br/monitoramento/

Barbosa, J.E.L.; Medeiros, E.S.F.; Brasil, J.; Cordeiro, R.S.; Crispim, M.C.B. \& Silva, G.H.G. 2012. Aquatic systems in semi-arid Brazil: limnology and management. Acta Limnol. Bras. 24(1): 103-118.

Brito, M.T.S.; Diniz, L.P.; Silva-Cavalcanti, J.S. \& Melo Júnior, M. 2011. Protocolos de avaliação ambiental rápida de açudes do Semiárido: Adaptações regionais e um estudo de caso. In: Messias, A.S. \& Feitosa, M.C.A. (Org.) A influência das mudanças climáticas sobre os recursos hídricos. $6^{\circ}$ Edição. Recife: UNICAP. 130-137pp.

Callisto, M.; Moretti, M. \& Goulart, M. 2001. Macroinvertebrados bentônicos para avaliar a saúde de riachos. Rev. Bras. Recur. Hídr. 6(1): 71-82.

Callisto, M; Ferreira, W.R.; Moreno, P.; Goulart, M. \& Petrúcio, M. Aplicação de um protocolo de avaliação rápida da diversidade de habitats em atividade de ensino e pesquisa (MG- RJ). 2002. Acta Limnol. Bras.14(1): 91-98.

Figueirêdo, M.C.B.; Teixeira, A.S.; Araújo, L.F.P.; Rosa, M.F.; Paulino, W.D.; Mota, S. \& Araújo, J.C. 2007. Avaliação da vulnerabilidade ambiental de reservatórios à eutrofização. Eng. Sanit. Ambient. 12(4): 399-409.

Firmino, P.F.; Malafaia, G. \& Rodrigues, A.S.L. 2011. Diagnóstico da integridade ambiental de trechos de rios localizados no município de Ipameri, sudoeste do estado de Goiás, através de um protocolo de avaliação rápida. Braz. J. Aq. Sci. and Tech. 15(2): 1-12.

França, L.O; Rodrigues, A.S.L. \& Malafaia, G. 2013. Diagnóstico ambiental do córrego do Açude, Orizona -GO por meio de um protocolo de avaliação rápida de rios. R. Trop. Ci. Agr. Bio. 7(1): 33-44.

Hannaford, M.J.; Barbour, M.T.; Resh, J.H.1997. Training Reduces Observer Variability In Visual Based Assessments Of Stream Habitat. J. N. Am. Benthol. Soc.16(4):853-860.
Lodi, S.; Vieira, L.C.G.; Velho, L.F.M.; Bonecker, C.C.; Carvalho, P. \& Bini, L.M. 2011. Zooplankton Community Metrics as Indicators of Eutrophication in Urban Lakes. Nat. Conserv. 9(1): 87-92.

Machado, C.J.S. 2003. Recursos hídricos e cidadania no Brasil: limites, alternativas e desafios. Ambiente Soc. 4(2): 120-136.

Nogueira, M.G; Ferrareze, M.; Moreira, M.I. \& Gouvêa, R.M.; 2010. Phytoplankton assemblages in a reservoir cascade of a large tropical-subtropical river (SE, Brazil). Braz J Biol 70(3): 781-793.

Rodrigues, A.S.L.; Castro, P.T.A. \& Malafaia, G. 2010. Utilização de protocolos de avaliação rápida de rios como instrumentos complementares na gestão de bacias hidrográficas envolvendo aspectos da geomorfologia fluvial: uma breve discussão. Enciclopédia Biosfera. 6(11): 1-9.

Rodrigues, A.S.L.; Malafaia, G. \& Castro, P.T.A. 2008. Avaliação ambiental de trechos de rios na região de ouro Preto-MG através de um protocolo de avaliação rápida. Rev. Estud. Ambiente. 10(1): 74-83.

Togoro, E.S. 2006. Qualidade da água e integridade biótica: estudo de caso num trecho fluminense do Rio Paraiba do Sul. Tese Doutorado. Universidade do Estado do Rio de Janeiro. 184p.

Vargas, J.R.A\& Ferreira Júnior, P.D. 2012. Aplicação de um protocolo de avaliação rápida na caracterização da qualidade ambiental de duas microbacias do Rio Guandu, Afonso Cláudio, ES. Rev. Bras. Recur. Hídr. 17(1): 161-168.

Submetido: Março/2015

Revisado: Dezembro/2016

Aceito: Fevereiro/2016 